\title{
NOTA SOBRE LA AMPLIACIÓN DE UN POZO MUDÉJAR EN MURCIA EN 1748
}

\author{
Juan B. Vilar* \\ José Iniesta Magán*
}

\section{NOTA PRELIMINAR}

Murcia es acaso una de las ciudades españolas que ha sufrido transformaciones más profundas en los tres últimos siglos. La ciudad medieval, que sobrevivió en considerable medida hasta el siglo XVIII, fue demolida en esa centuria en momentos de desarrollo demográfico y expansión económica sin precedentes, para edificar sobre ella otra ciudad, a su vez arrasada en los años cincuenta, sesenta y setenta de este siglo bajo los efectos de otro espectacular auge expansivo.

Hoy apenas queda nada de la Murcia musulmana. Sus más emblemáticos monumentos han desaparecido (murallas, alcázar real, mezquitas, palacios, lonjas de contratación, alquerías residenciales en sus inmediaciones..., etc.), y todo o casi todo ha sucumbido en el curso del tiempo bajo el golpe de la piqueta, devorado por una fiebre renovadora indiscriminada e insensata, en algún caso en fecha bien reciente (los Baños Árabes destruidos por sorpresa en los primeros años 50). Ello es tanto más penoso por tratarse de una de las dos o tres únicas grandes ciudades españolas fundadas ex novo en la etapa musulmana, y que por su magnificencia y por los grandes hombres que dio en esa época su nombre es conocido y reverenciado dentro y fuera del ancho mundo islámico.

Afortunadamente se ha entrado en una andadura de revalorización del legado del Islam, algunos de cuyos vestigios murcianos continúan siendo importantes (urbanismo del casco antiguo, sistema de riegos en la huerta, etc.). Al propio tiempo, se intenta preservar y restaurar los escasos restos monumentales y arqueológicos salvados de una incuria secular, y los que por fortuna no dejan de ir apareciendo (dispersos vestigios de la muralla al-

* Universidad de Murcia. 
mohade, cementerio islámico de Santa Eulalia, claustro mudéjar de Santa Clara, estructuras de varias mansiones privadas, mezquita-iglesia de Santa Catalina, artesonados en diferentes templos de los siglos XIV, XV y XVI, etc.), protegidos hoy por la ley y cuyo rescate se halla confiado a expertos y entusiastas especialistas, dependientes de instituciones municipales (Instituto "Ibn Arabi"), regionales (Cultura, Bellas Artes) y universitarias (diferentes Departamentos), que aunque un tanto descoordinadamente y con medios insuficientes, realizan empero una labor benemérita y destacable.

El grave daño sufrido por el patrimonio arqueológico-monumental potencia la importancia de los testimonios documentales, cuyo valor como instrumentos de apoyo resulta difícilmente exagerable, por insignificantes que parezcan. De ahí el interés de dar a conocer el documento notarial adjunto, un testimonio más de la pervivencia, siquiera parcial, varios siglos después de su introducción, de la infraestructura para el aprovisionamiento urbano de agua creado en Murcia en época islámica.

En el Archivo Histórico Provincial de Murcia, Sección de Protocolos Notariales, n² 2.981, escribano Esteban González y año 1748, ff. 443r-444v, se contiene una escritura de obligación de cierto Antonio Benítez, vecino de Murcia y maestro carpintero, referida a un pozo reputado de "morisco", situado en una finca urbana (inmediata a la plazoleta de Bussi, hoy Puxmarina) propiedad del convento de Santo Domingo, en la misma ciudad.

La fecha del documento coincide con el momento de máxima euforia constructora en Murcia durante todo el siglo, contemporáneo del pontificado del emprendedor obispo don Juan Mateo López (1742-1752), en cuyo tiempo es acelerado el proceso de transformación de la vetusta ciudad de raigambre islámica en otra más en consonancia con los tiempos. Una ciudad embellecida con la remodelación de plazas y calles, diseño de espacios abiertos junto al río y con nuevos y en ocasiones excelentes edificios tanto eclesiásticos como civiles (construcciones de uso oficial, mansiones diversas, templos parroquiales de San Nicolás y San Antolín, conventos de Santa Verónica, San Agustín y Santa Teresa, capilla del Pilar, oratorio de los Peligros, etc.). Transformación al frente de la cual figuran por derecho propio el trazado de la actual plaza del Cardenal Belluga y la edificación en la misma del imafronte de la fachada principal de la catedral y el palacio episcopal, realizados por el valenciano Jaime Bort y el italiano Baltasar Canestro (empeños ambos del obispo López), construcciones, que con la torre de la iglesia matriz (a la que en esta época fue añadido un cuerpo) son hoy las más emblemáticas de la ciudad.

Digno ciudadano de esta urbe en plena expansión era Antonio Benítez, maestro carpintero como queda dicho, a quien debían ir muy bien las cosas. 
Resultándole insuficiente el inmueble que para vivienda y taller tenía tomado en arrendamiento vitalicio a sus propietarios, la comunidad local de frailes dominicos, compró el solar colindante, donde hizo levantar casa de nueva planta, con acceso a la céntrica plazuela de Bussi, parroquia de San Bartolomé, situada entre la de Santa Catalina (centro tradicional de la ciudad) y la entonces recién abierta junto a la nueva fachada principal de la catedral. Por tanto en un punto que entonces como ahora se halla en el cogollo mismo de la urbe.

Como quiera que la finca edificada careciese de "...capacidad y sitio cómodo donde poderse fabricar pozo", Benítez... "de su propia autoridad y sin licencia, ni expreso permiso de dicho Real Convento, desanchó [sic] el pozo morisco que tenía la casa de él, para hacerlo medianero de la suya, como con efecto lo hizo, y sintiéndose de ello en gran manera agraviado dicho Convento, mandó se cerrase dicho pozo por la parte que toca a la casa del otorgante, para que esta no tuviera servidumbre de él".

El documento de referencia habla de "pozo morisco", aunque más propiamente debería decir mudéjar, por corresponder sin duda a uno de los numerosos inmuebles requisados a la comunidad musulmana en el momento de la reconquista. Los pobladores islámicos hubieron de retirarse en bloque al barrio extramuros de la Arrixaca, en adelante morería local, que cubría aproximadamente las actuales parroquias de San Andrés y San Antolín.

El pozo debía ser de sólida construcción por hallarse todavía en uso. Situado en la expresada finca de los dominicos, pero junto a la pared medianera de la adquirida en propiedad por el inquilino de los frailes, éste había ideado asegurar la necesaria provisión de agua a su nueva residencia ampliando el diámetro del pozo existente, de forma que quedara partido por la mitad entre ambas fincas.

Obviamente los frailes predicadores, la comunidad religiosa más antigua de Murcia, y también una de las más ricas e influyentes, mendicante por definición es cierto, pero muy cuidadosa de sus bienes, rentas e intereses terrenales, no se dejó burlar por el ladino carpintero. Si éste, según parece, eligió deliberadamente el momento de ensanchar en beneficio propio el pozo ajeno, aprovechando que los dominicos andaban afanados en la organización de las fiestas de canonización de santa Catalina de Rizzis, las más fastuosas que conociera la ciudad en mucho tiempo, erró en sus cálculos. Los frailes, es cierto, echaron la casa por la ventana y gastaron una fortuna en el festejo, que duró semanas, pero no toleraron la invasión de una de sus propiedades, por insignificante que resultara el perjuicio.

En consecuencia, exigieron la demolición de la obra hecha para que el pozo quedara exclusivamente en su finca tal como siempre lo había estado. Pero "....habiéndose interpuesto algunas personas de autoridad, se convinieron dicho Convento y el otorgante en que éste había de hacer una pared medianera de medio ladrillo desde el suelo de dicho pozo", de forma que 
ambas fincas pudieran disfrutar del mismo con entera independencia. Los dominicos se reservaban además, caso de que así conviniera a sus intereses futuros, el derecho de hacer inutilizar la mitad que daba al inmueble que Benítez poseía en propiedad. Entre tanto, éste quedaba obligado a cuidar de la pared interna del pozo y a "...mantenerla corriente de todo cuanto necesitara".

Inmueble y pozo subsistieron hasta bien entrado el siglo actual, en que desapareció con la casi totalidad de las edificaciones del entorno, al procederse a la apertura de la Gran Vía. Esta reforma supuso la remodelación tota] del espacio ocupado por la actual Plaza Puxmarina (de Bussi en 1748), con la consiguiente demolición del inmueble que fuera de Benítez (o lo que del mismo subsistía) y del pozo mudéjar adyacente. Pero también de construcciones más importantes, tales como el antiguo monasterio de Madre de Dios (de religiosas justinianas) y los no menos reseñables Baños Árabes.

\title{
APÉNDICE DOCUMENTAL
}

\author{
AHPM, Protocolo n." 2.981 (Año: 1748. Escribano: González, Esteban), ff. 443r-444v.
}

Real Convento del Señor Santo Domingo de esta ciudad. Escritura de declaración y obligación contra Antonio Benitez, vecino y maestro carpintero en Murcia.

"En la ciudad de Murcia, a veintiún días del mes de noviembre del mil setecientos cuarenta y ocho años, ante mí el escribano público y testigos pareció Antonio Benítez, vecino y maestro de carpintero de dicha ciudad.

Y dijo que, habiendo fabricado una casa desde cimientos en la población de ella, parroquia del Señor San Bartolomé, en la plazuela que dicen de Bussi, inmediata y contigua a otra en que habita y tiene por arrendamiento vitalicio, propia del Real Convento del Señor Santo Domingo de esta referida ciudad, por no tener aquella capacidad y sitio cómodo donde poderse fabricar pozo, estando como están la una contigua a la otra, el otorgante, de su propia autoridad y sin licencia, ni expreso consentimiento de dicho Real Convento, desanchó el pozo morisco que tenía la casa de él, para hacerlo medianero de la suya, como con efecto lo hizo, y sintiéndose de ello en gran manera agraviado dicho Convento, mandó se cerrase dicho pozo por la parte que toca a la casa del otorgante, para que ésta no tuviera servidumbre de él.

$Y$ habiéndose interpuesto algunas personas de autoridad, se convinieron dicho Convento y el otorgante en que éste había de hacer una pared medianera de medio ladrillo desde el suelo de dicho pozo. Y que ésta había de permanecer por el tiempo que pareciera al mencionado Real Convento, pudiendo cerrar la parte del pozo que cae a la casa del otorgante siempre que le tuviera cuenta y quisiera, o antes, si a éste fuere de su conveniencia el ejecutarlo, y obligarse interin y en el tiempo [en] que existiera dicha pared a mantenerla corriente de todo cuanto necesitara.

Y permaneciendo existente al presente en ambas casas el referido pozo sin haberse practicado dicha pared, se le ha pedido al otorgante por parte del citado Real Convento, 
que para que en todo tiempo conste la realidad de todo lo relacionado, lo declarará así y se obligará a ello, como también a no interesar cosa alguna, si dicho Real Convento quisiera levantar en algún tiempo dicha su casa, por lo tocante a medianería, respecto de haberse el otorgante aprovechado, y metido en su casa para su mayor desanche, medio palmo de sitio de la pared divisoria que hay en las entradas de dichas dos casas, por haberse así en la misma forma convenido.

$Y$ viendo ser justo lo susodicho, lo ha tenido a bien, y dando como da por cierta y verdadera la relación de esta escritura. Declara haberse convenido y ajustado en la forma sobredicha con el referido Real Convento, y se obliga a hacer y construir dicha pared medianera de medio ladrillo a toda satisfacción desde el suelo de dicho pozo. Y a mantenerla corriente de cuanto precise interin y por el tiempo que fuese la voluntad de dicho Convento, o mande cerrar la parte del pozo que toca y cae a la casa del otorgante, y antes si a este le tuviera cuenta.

Y también se obliga a que si en lo venidero, dicho Real Convento quisiere levantar su casa como dicho es, a no interesar cosa alguna, por lo respectivo a la medianería, por darse como se da por pagado y satisfecho de su valor, en el que puede tener el palmo de sitio que va dicho se ha aprovechado el otorgante y metido en su casa para su mayor ensanche, de la pared medianera que hay en las entradas de dichas dos casas.

Ya que habrá por firme esta escritura, obligó su persona y bienes muebles y raíces habidos y por haber, y sin que la hipoteca especial derogue la obligación general, ni por el contrario porque de ambos derechos se ha de poder usar, hipoteca la referida casa que ha dicho ha fabricado, y linda por levante con la referida placeta de Bussi, donde se halla, [a] mediodía y poniente con casas de los herederos de Juan Gómez, y por el norte con la casa citada de dicho Real Convento. $Y$ es franca de todo gravamen, para que esté sujeta, gravada, obligada, e hipotecada al cumplimiento de esta escritura con prohibición absoluta de su enajenación y cláusula irritante de non alienando, según y en la forma que lo previene el derecho.

Y para su ejecución dio poder a las Justicias y Jueces de S.M. de cualesquier partes que sean, para que a lo que dicho es le condenen, compelan y apremien, como si fuera por sentencia pasada en autoridad de cosa juzgada, renunció las leyes, fueros y derechos de su favor y la general en forma. En cuyo testimonio así lo otorgó y firmó, siendo testigos, D. Pascual Pérez Osa, D. Juan Asensio Cazorla y Miguel Tomás, vecinos de esta ciudad, a todos los cuales yo el escribano doy fe conozco:= Antonio Benítez.= Ante mí, Juan Gon$z a ́ l e z .=$ Sin derechos, doy fe".

\section{RESUMEN}

La pérdida de la casi totalidad del patrimonio arqueológico-monumental murciano de la época musulmana potencia el interés de los testimonios documentales por insignificantes que parezcan. El documento notarial aportado da fe de la existencia en Murcia a mediados del siglo XVIII, y en perfecto funcionamiento, de un pozo "morisco" (mudéjar en realidad) en un inmueble perteneciente a la comunidad local de religiosos dominicos, la más antigua de la ciudad, y que acaso lo recibiera en los repartimientos alfonsinos tras la conquista, situado en la céntrica plazoleta de Bussi (hoy Puxmarina por ubicarse allí la antigua mansión de los Puxmaría). El pozo de referencia 
es sin duda una interesante supervivencia del sistema urbano de aprovisionamiento de agua en la Murcia medieval.

\begin{abstract}
The loss of nearly all the archaeological-monumental patrimony of the Moslem period in Murcia grants the interest of the written testimonies even if they seem insignificant. The provided "notarial" document vouches for the existence of a "Moorish" (Mudejar in reality) well in a building belonging to the local community of Dominican monks in Murcia in the middle of the 18th century, and in perfect operation. This was the most ancient religious community in the city, and they might have received it when the "repartimientos alfonsinos" took place after the conquest. The well, located in the central small circus of Bussi -today Puxmarina because the ancient mansion of the Puxmaría is placed there- is without doubts an interesting survival of the urban system of water supplies in Murcia in the medieval times.
\end{abstract}

